\title{
ПРИМЕНЕНИЕ ГЕОФИЗИЧЕСКИХ МЕТОДОВ ДЛЯ РЕШЕНИЯ ИНЖЕНЕРНО-ГЕОЛОГИЧЕСКИХ ЗАДАЧ ПРИ ИССЛЕДОВАНИИ ОПОЛЗНЕВЫХ ПРОЦЕССОВ В ОКТЯБРЬСКОМ УЩЕЛЬЕ ГОРОДА САРАТОВА
}

О.Д. Смилевец ${ }^{1}$, А.В. Иванов, Н.В. Хаюк ${ }^{1}$, К.А. Кравцова ${ }^{1}$, А.Г. Кузин

Саратовский государственный университет, кафедра геоэкологии

E-mail: geoecologia@info.sgu.ru

${ }^{1}$ Саратовский государственный технический университет, кафедра производства строительных изделий и конструкций E-mail: Smilevets@mail.ru

В статье рассматривается применение комплекса геофизических методов исследований и современной аппаратуры для решения практических инженерно-геологических задач при проектировании строительства технических сооружений на оползневых склонах (участках).

Application of Geophysical Methods for the Decision of Engineering - Geological Problems at Research Landslip Processes in October Gorge of City of Saratov

\section{O.D. Smilevets, A.V. Ivanov, N.V. Hajk, K.A. Kravtzova,} A.G. Kuzin

In article application of a complex of geophysical methods of researches and the modern equipment for the decision of practical and engineering - geological problems is considered at designing for construction of technological constructions on landslip slopes (sites)

Под оползнем понимают деформацию грунтов, оседание и перемещение вниз по склону горных пород вследствие обводнения. Оползневые явления могут причинять техническим сооружениям всех видов значительный урон. Для разработки эффективных противооползневых мероприятий необходимо тщательное изучение геологических и гидрогеологических условий оползневого участка. Практикуемые в настоящее время разведочные работы (бурение, шурфовка) требуют больших затрат времени и средств, что затрудняет широкое развитие данных работ на изысканиях. Поэтому большое значение имеет разработка и применение других, более экономичных методов инженерно-геологических исследований, в частности электроразведочных.

Инженерно-геологическими исследованиями в оползневом районе должны быть выявлены: геологическое строение, гидрогеологические условия и геоморфологические особенности района оползня, внутренние причины движения оползневых масс (консистенция, гидродинамическое давление, суффозия и др.); факторы, способствующие оползанию (условия питания склона поверхностными и подземными водами, характер конфигурации и нагруженности склона, выветривание, подмыв основания, деятельность человека и пр.); характер оползней по форме кривой скольжения (очень пологие, пологие, крутые, очень крутые), по глубине захвата (поверхностные, мелкие, глубокие, очень глубокие) и по времени появления и состояния (свежие, старые, древние, действующие, недействующие и пр.); физико-механические свойства горных пород.

Изучаемый оползень сформировался в левом обрывистом борту Октябрьского ущелья между обустроенным каптированным родником и ЛЭП-110 кВ. Западная граница оползня совпадает с тальвегом, в котором расположены каптажные сооружения Октябрьского родника. Восточная граница оползня проходит в 50 м к западу от ЛЭП-110, параллельно линии электропередач. Ширина оползня по фронту составляет 200 м. Длина оползня от тылового шва до окончания фронтального языка составляет 150 м. Площадь оползневого тела составляет 25-30 тыс. м², общая масса - около 0,5 млн т.

Характерной особенностью оползня является тесная связь его с участками разгрузки подземных вод, в том числе с Октябрьским родником. Свежие оползневые трещины отрыва веером расходятся от тальвега с каптажными сооружениями в восточном направлении, закладываясь от уровня разгрузки подземных вод в роднике.

Октябрьский оползень начал активно проявляться с лета 2004 года. В последней декаде сентября 2004 г. дебит Октябрьского родника составил более $4 \mathrm{~m}^{3} /$ ч. Подвижки оползня привели к деформации и перегибу трубы из каптажного колодца и уменьшению дебита из трубы до 0,09 м³ в последней декаде июля 2005 года. Подвижки оползня оборвали водоводную трубу диаметром 200 мм, проложенную из города до санатория «Октябрьское ущелье». Наибольшая подвижка оползня произошла в марте-апреле 2005 г., когда горизонтальная амплитуда составила несколько метров и язык оползня, повалив деревья в возрасте нескольких десятков лет, выполз к тротуарной дорожке.

Наблюдения с поверхности и результаты буровых работ показали, что оползень имеет ярко выраженные зеркала скольжения со швами и бороздами трения. В случае дальнейшего переувлажнения оползневые массы способны к дальнейшему движению, что может привести к пе- 
рекрытию автодороги, разрушению придорожных коммуникаций и прочих сооружений. Расширение оползня по фронту может привести к возникновению прямой угрозы ЛЭП-110 кВ.

Движение оползня следует ожидать в периоды длительных дождей в связи с тем обстоятельством, что трещины отрыва растяжения бровки срыва открыты и будут с максимально возможной интенсивностью насыщаться атмосферными, поверхностными и подземными водами.

Разрез оползневой системы сложен меловыми, палеогеновыми и четвертичными отложениями.

\section{Верхнемеловые отложения}

В пределах изучаемого оползневого тела Октябрьского ущелья наиболее древними являются отложения сеноманского яруса верхнего отдела меловой системы $\left(\mathrm{K}_{2} \mathrm{~s}\right)$. Эти отложения наблюдаются в низовой части оползня и днища ущелья под оползневыми и делювиальными образованиями. Кровля их фиксируется на абсолютных отметках 140,0-143,0 м. Отложения представлены песчаной пачкой.

$\mathrm{K}_{2} \mathrm{~s}$ 1. Песок кварцево-глауконитовый, серо-зеленый, мелкозернистый, алевритистый, гидрослюдистый слабо пронизан ходами донных роющих организмов. Остатки фоссилий редки, большей частью приурочены к фосфоритовому горизонту. Мощность около 30 м. Вниз по разрезу слой постепенно переходит в пески и глины альбского возраста. Однако этот переход располагается ниже уровня Октябрьского ущелья и не затронут оползневой ситуацией. Мощность отложений оценивается в среднем 30-40 м.

$\mathrm{K}_{2}$ st 2. Мергель (силицито-глино-известняк) песчанистый, грязно-белый, с обилием глауконита и включений фосфоритов, количество и размеры которых уменьшаются вверх по разрезу. Фосфориты и фрагменты скелетов губок образуют в нижней половине скопления в виде тонких невыдержанных прослоев, линз. В верхней части слоя содержание терригенной составляющей уменьшается и проявляются тонкие прослои окремнения синего цвета с редкими мелкими фосфоритами. Выше прослоев окремнения включения отсутствуют. По комплексу губок и двустворчатых моллюсков возраст вмещающих отложений определяется как нижнесантонский (возможно, верхи нижнего сантона). Мощность 0,75-1 м.

Выше залегает так называемая «полосатая серия» сантона - ритмичное переслаивание мергелистых различных глин и опок, в которой литологически выделяются две пачки.

$\mathrm{K}_{2}$ st 3. Кремнистая пачка - большую часть составляют глинистые или известково-глинистые силициты, в которых неравномерно распределены слои известковых глино-силицитов и силицитоглин. Часто встречаются остатки двустворчатых моллюсков и ростры белемнитов, известны на- ходки чешуи рыб, редкие одиночные кораллы. Мощность 8,1 м.

$\mathrm{K}_{2}$ st 4. Карбонатно-глинисто-кремнистая пачка, постепенно сменяющая подстилающий слой. Представлена в нижней части известковоглино-силицитами, которые незаметно переходят в известково-глинистые силициты и выше - в известковистые глино-силициты. Возраст этого слоя рассматривается как позднесантонский [1]. Мощность около 15-17 м.

$\mathrm{K}_{2}$ ср 5. В составе слоя выделяется ряд интервалов, описанных по серии закопушек и по аналогии с разрезом Завокзального ущелья [1]:

а. Мергель песчанистый, обогащен глауконитом, серо-зеленый. В подошве слоя наблюдаются крупные (до 5-12 мм) окатыши светло-коричневых фосфоритов. Глинисто-силицитовый материал с глауконитом заполняет многочисленные ходы роющих организмов, сильно изменивших облик кровли подстилающих пород. Зерна глауконита сгружены в виде линз и гнезд неправильных очертаний. Мощность прослоя 0,3 м.

б. Выше по разрезу - рыхлые мергели глауконитовые, силицитовые. Здесь встречены редкие, равномерно рассеянные по слою остатки фоссилий в автохтонном захоронении. Среди них характерны ростры белемнитов, раковины иноцерамов и других двустворчатых моллюсков, скелеты губок плохой сохранности. Мощность прослоя 0,3-0,5 м.

в. Еще выше наблюдается хорошо выраженный в профилях обрывов и склонов оврагов в виде уступа известняк глинисто-силицитовый с обилием глауконита (до 40\%). Характерно неравномерное прокремнение слоя, что придает ему вид линзовидного прослоя. В его основании наблюдаются небольшие, черно-коричневые фосфориты, которые реже встречаются в рассеянном состоянии вверх по слою. В аналогичном слое Завокзального ущелья [1] остатки скелетов губок в большей степени приурочены к нижней половине интервала, встречаются ростры белемнитов, очень крупные (более 1,5 м) ядра аммонитов, тела позвонков мозазавров, зубы селяхий, копролиты и ядра скафопод. Мощность 0,4-0,6 м.

г. Выше залегают рыхлые силицитовые мергели с глауконитом и редкими мелкими фосфоритами, содержащие отдельные крупные ядра аммонитов. В кровле порода сцементирована кремнистым цементом и несколько увеличивается содержание фосфоритов. Мощность прослоя 0,8-1 м. Общая мощность слоя 2-2,2 м.

$\mathrm{K}_{2}$ cp 6. Кремнисто-глинистая пачка, представленная чередующимися прослоями серых опок и черных кремнистых глин. Мощность слоя 5-7 M.

$\mathrm{K}_{2} \mathrm{~m} 7$. Верхняя часть кремнисто-глинистой пачки, почти полностью лишнная карбонатной составляющей. В основании слабо проявлен прослой редких желваков и зерен фосфорита, которые совместно с алевритовым и псаммитовым 
материалом образуют линзы и гнезда. Данные отложения относятся к зоне Belemnella licharevi нижнего маастрихта. Мощность 1-2 м.

$\mathrm{K}_{2} \mathrm{~m}$ 8. Мергель светло-серый, слабо песчанистый, в выветренном состоянии плитчатый. Распространены раковины устриц, которые образуют местами небольшие линзовидные прослои, а также ростры белемнитов. Мощность 15-17 м.

\section{Палеогеновые отложения}

Сызранская свита $\left(\mathbf{P}_{\mathbf{1}} \mathbf{s z}_{1}\right)$. Сызранская свита на обследованном участке представлена слоями, сложенными опоками с единичными прослоями глины. Опоки сильнотрещиноватые, рассеченные серией тектонических субвертикальных трещин северо-восточного простирания, а также трещинами отдельности, трещинами напластования и выветривания.

\section{Четвертичные отложения}

Образования древнего оползня $\left(\mathrm{dpQ}_{\mathrm{IIIIV}}\right)$. Представлены глинами с примесью щебня опоки и мергеля. Мощность отложений в голове древнего оползня достигает 10,0 м.

Образования современного оползня $\left(\mathrm{dpQ}_{\mathrm{IV}}\right)$ выражены в разрезе суглинком, щебнем опоки с почвой, прослоями дресвяно-щебенистого грунта. Толща оползневых грунтов сильно разуплотнена многочисленными трещинами отрыва и растяжениями, на отдельных участках она переувлажнена.

Пролювиально-делювиальные отложения $\left(\mathrm{prIQ}_{\mathrm{IV}}\right)$ слагают днище Октябрьского ущелья и представлены глинами с примесью слабоокатанного щебня, дресвы и суглинками с примесью обломочного материала, имеют мощность 7-15 м и залегают на коренных песках сеноманского яруса верхнего мела с размывом.

Базисом оползневых явлений в районе работ являются сеноманские отложения.

Уровень грунтовых вод зафиксирован на глубине 8 м. Направление грунтового потока прослеживается на юг и юго-восток. В рассматриваемом районе известны три водоносных горизонта: сызранский $\left(\mathrm{P}_{1} \mathrm{sz}\right)$, сантон-кампанский $\left(\mathrm{K}_{2} \mathrm{st}-\mathrm{K}_{2} \mathrm{~km}\right)$ и сеноманский $\left(\mathrm{K}_{2} \mathrm{~cm}\right)$. Установлено, что выходы родниковых вод Октябрьского ущелья наблюдаются над кампанскими глауконит-кварцевыми песчаниками. В свою очередь, формирование родников связано с перетоками вод из вышележащих водоносных горизонтов. В этой связи в формировании подземных вод, насыщающих оползневое тело и служащих первопричиной оползнеобразования, принимают участие водоносные горизонты сызранского и сантон-кампанского возраста.

В течение мая-октября 2005 г. были проведены комплексные полевые инженерно-геологические и геофизические исследования на оползневом участке в Октябрьском ущелье Саратова (рис. 1). Основными задачами изысканий являлись:
- оценка по геофизическим данным и бурению скважины глубиной 30 м, литологического строения и мощности рыхлых оползневых масс в плане и по разрезу;

- выяснение уровня залегания подземных вод (УГВ) в теле оползня, глубины залегания коренных пород;

- определение по результатам опробования пройденной скважины физико-механических свойств пород;

- детальное изучение геофизической (геоэлектрической) модели верхней части разреза;

- картирование поверхностей современного и древнего оползней;

- оконтуривание языка современного оползня;

- прогноз динамики развития оползневых процессов.

Условия проведения комплексных полевых геофизических исследований осложнены резко пересеченным рельефом участка развития современных и древних оползневых процессов, крутым склоном, наличием подземных и наземных коммуникаций городской инфраструктуры, что создавало высокий уровень техногенной помехи на фоне регистрируемых сигналов.

\section{Электроразведка МЗСБ}

Электроразведка методом вертикального электрического зондирования (ВЭЗ) выполнялась для получения параметрической информации о геоэлектрических характеристиках грунтов в интервале развития современных оползневых процессов [2]. Использовалась цифровая измерительная аппаратура (ЭРП-1) и аналоговая - электроразведочный стрелочный компенсатор (АЭ-72). Сеть наблюдений в методе ВЭЗ - профильная (по единой координатной сети), с шагом приемно-питающей установки 25-50 м, с разносами питающей линии $\mathrm{AB} / 2=75$ м. Питающая линия AВ включала 12 действующих разносов. Центры установок размещались на координатных пикетах профильной сети наблюдений. Питающая и приемная установки ориентировались по линиям с минимальными превышениями рельефа. Количество выполненных координатных точек ВЭЗ на трех профилях - 30 (ПР1, 2, 3) [3, 4].

Зондирование становлением электромагнитного поля в ближней зоне (МЗСБ) выполнялось с целью детального изучения геоэлектрических характеристик разреза (в интервале глубин от 5 до 40 м), определения глубин залегания опорных геоэлектрических границ, прогноза литологического состава и гидрогеологических характеристик. Использовалась электроразведочная аппаратура (Цикл-6). На координатных пикетах профильно-площадной сети наблюдений размещались многоразмерные осесимметричные совмещенные установки $\left(L_{1}=8\right.$ м и $L_{2}=20$ м). Количество координатных точек на исследованном участке МЗСБ-40 (ПР1,2,3,4). 


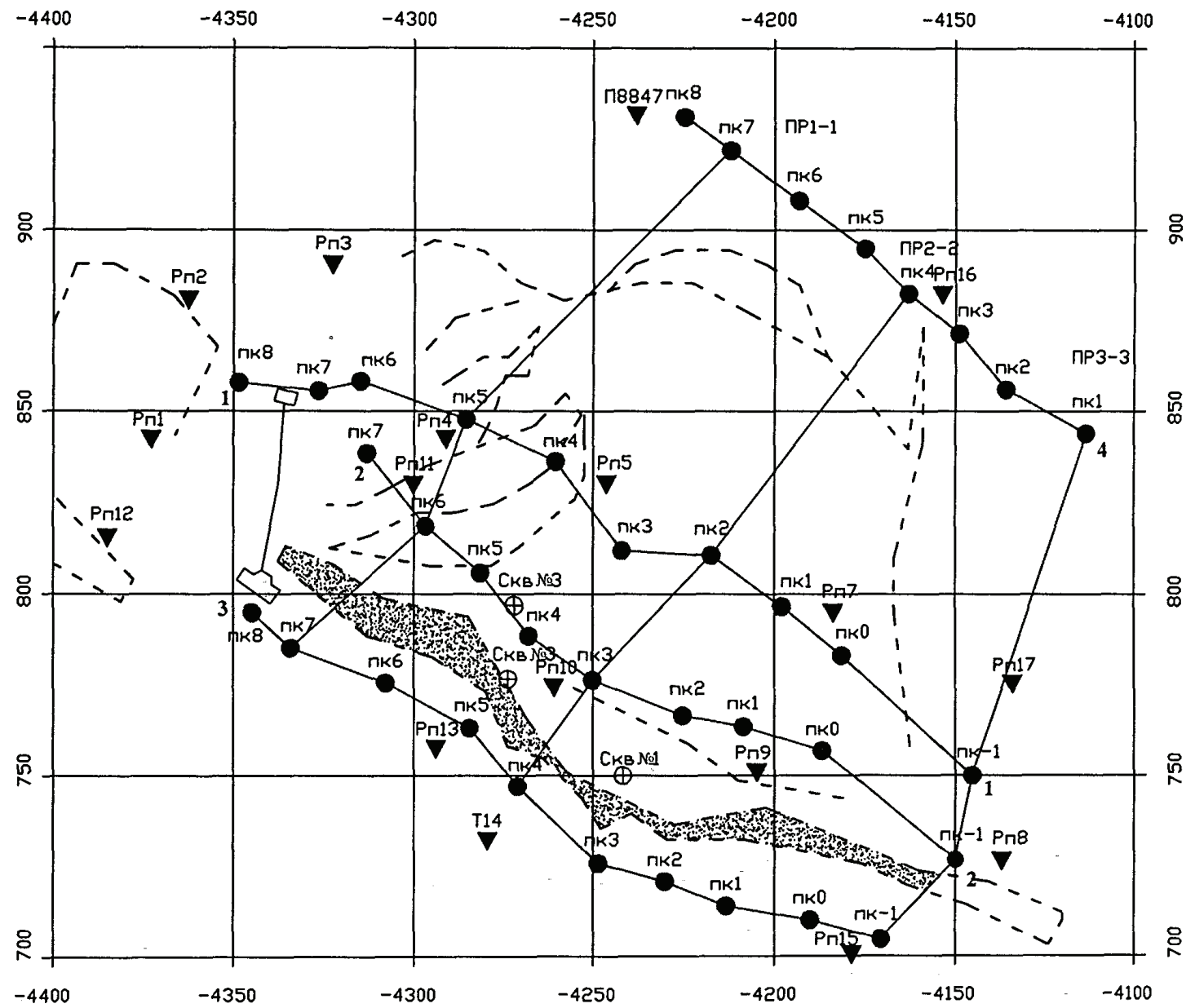

Условные обозначения:

пк 1 пк 2 - пикеты и профили геофизических наблюдений;

\section{1, 2, 3 - номера геофизических профилей; \\ скв.№ 1 - инженерно-геологическая скважина \\ $\oplus$ и ее номер;}

Рп 15 - репер наблюдательной сети и его номер;

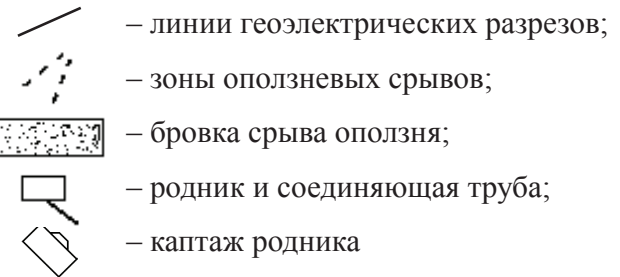

Рис. 1. Схема размещения геофизических профилей на участке исследований (Октябрьское ущелье)

Обработка и интерпретация полевых записей выполнялась с использованием специальных программ для каждого из методов.

Интерпретация кривых ВЭЗ проводилась по трехслойным палеткам фирмы «Шлюмберже», палеткам А.М. Пылаева и методике В.А. Шамшурина. При отождествлении геоэлектрических зон с определенными литологическими горизонтами геоэлектрические разрезы приобретают конкретный геологический смысл $[5,6]$.

Информативность полевых записей сейсморазведки методом преломных волн (МПВ), в связи с неблагоприятными сейсмогеологическими условиями (наличие мощного верхнего низкосортного слоя: оползневая толщина - рыхлые суглинки с дресвой), оказалась весьма низкой.
Электроразведкой методом ВЭЗ изучены геологические характеристики разреза по трем профилям.

Разрез в изученном интервале глубин по данным ВЭЗ аппроксимируется трехслойным, четырехслойным типом кривых $H-Q K H$.

Результаты интерпретации данных ВЭЗ по трем профилям в виде разрезов кажущегося электрического сопротивления представлены на рис. 2. Первый от поверхности геоэлектрический слой высокоомный, сопротивление его изменяется в широких пределах от 200 до 1000 Ом`м, мощность слоя 0,1-0,5 м. По литологической характеристике слой соответствует сухим образованиям современного оползня, представленным щебнем опоки и почвенно-растительным покровом $\left(\mathbf{d p} \mathbf{Q}_{\mathbf{I V}}\right)$. 

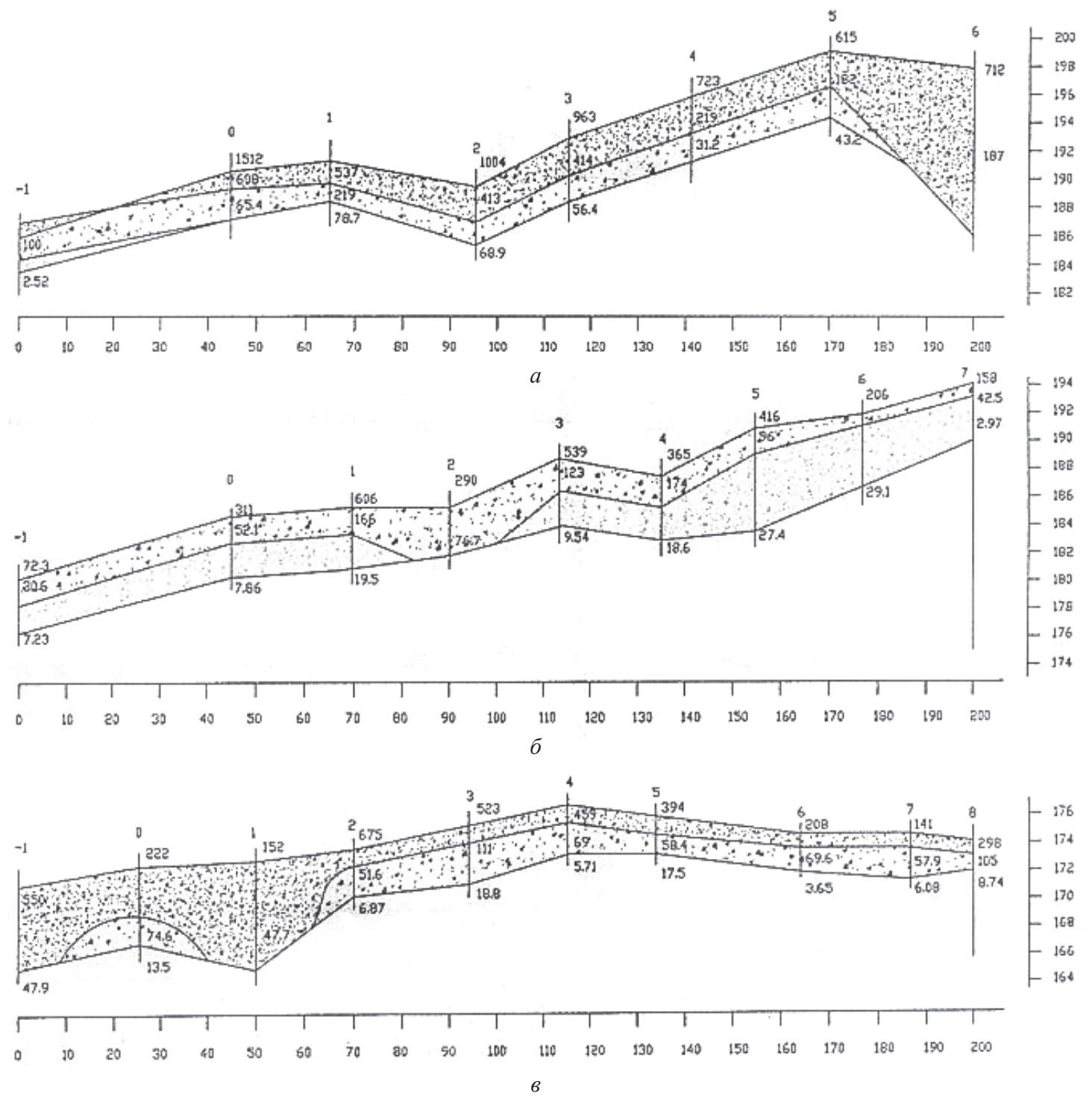

Рис. 2. Разрезы кажущегося электрического сопротивления по данным электроразведки ВЭЗ (Октябрьское ущелье): $a$-профиль $1 ; \sigma$ - профиль $2 ; 6$ - профиль 3

Ниже по разрезу выделен относительно низкоомный слой. Картируемая мощность слоя от 0,5 до 6 м. Кажущееся сопротивление изменяется от нескольких десятков до сотен омметров. В основании геоэлектрического слоя выделен еще более низкоомный прослой. Значения кажущегося сопротивления этого прослоя $\left(\rho_{k}\right)$ изменяются от нескольких единиц до первых десятков омметров. Мощность прослоя изменяется от 5 м до 0. Прослой коррелируется в разрезах по профилям фрагментарно. Подошва относительно низкоомного слоя коррелируется по данным ВЭЗ условно по минимуму $\rho_{k}$ перед асимптотическим подъемом правых ветвей кривых $\rho_{k}$, отражающих ограничение глубинности исследований с примененной установкой.

В распределении мощности и кажущегося сопротивления опорного относительно низкоом- ного геоэлектрического слоя, в плане, по данным ВЭ3, отчетливо прослеживаются контуры верхнего интервала современной оползневой толщи. В геоэлектрической характеристике она отражается аномально высокими значениями $\rho_{k}>50$ Ом·м при большом перепаде значений оцененной мощности этого слоя (от 2 до 8 м). Пониженными значениями $\rho_{k}<15$ Ом·м охарактеризована зона расположения каптажа, юго-западная и юго-восточная окраины обследованного участка.

По результатам электроразведки ВЭЗ изучены геоэлектрические характеристики самой верхней части разреза оползневого участка до глубин 6-8 м. Этот интервал не отражает полную мощность толщи современного оползневого участка.

Геоэлектрические характеристики исследуемого участка отличаются большой изменчивостью. На форму кривых ВЭЗ оказывают влияние многие 
факторы: литология, влажность, наличие наклонных и вертикальных границ раздела пород, ориентировка измерительной установки ВЭЗ и т. д.

Для определения горизонтальности залегания слоев изучаемых пород на месте пробуренной скважины было проведено круговое зондирование (КрВЭ3). Сравнение результатов измерений $\rho_{k}$, полученных при КрВЭЗ для одинаковых АВ/2, показало, что имеет место диаграмма вытянутой формы. Это свидетельствует о наклонном залегании слоев или наличии плоскостей раздела, образованных трещиноватостью пород.

Наличие крутого (часто равного $45^{\circ}$ ) наклона правой ветви кривой ВЭЗ свидетельствует о присутствии на глубине 30 м более высокоомных, чем в верхней части разреза пород и наклонной границе их кровли.

Наличие грунтовых вод на глубине 8 м отмечается искажением на кривой ВЭЗ типа «Н». Переслаивание пород различной дисперсности и литологического состава отмечается изломами на кривой ВЭЗ.

Наличие буровой скважины на участке работ позволило выявить связи удельного электрического сопротивления (УЭС) с литологией пород [6]. Некоторые данные по литологическому составу и соответствующим сопротивлениям представлены в таблице.

Сопоставление литологических данных и электрических сопротивлений на оползневом участке в Октябрьском ущелье

\begin{tabular}{|l|c|c|}
\hline \multicolumn{1}{|c|}{ Литология } & $\begin{array}{c}\text { Номер геоэлектрического } \\
\text { горизонта }\end{array}$ & $\begin{array}{c}\text { Удельные электрические } \\
\text { сопротивления, Ом·м }\end{array}$ \\
\hline Почвенно-растительный покров с щебнем опоки & 1 & $200-1000$ \\
\hline Щебень опоки & 2 & $10-20$ \\
\hline Суглинок тяжелый с примесью щебня (оползневой) & 3 & От 2-3 до 5-6 \\
\hline Суглинок и глина текучепластичная & 4 & $2-4$ \\
\hline $\begin{array}{l}\text { Чередование мергелей и глин } \\
\text { с прослоями песчаников }\end{array}$ & 5 & От 1-2 до 4-6 \\
\hline Чередование мергелей и кремнистых глин & 6 & $25-50$ \\
\hline Песок в коренном залегании & 7 & \\
\hline
\end{tabular}

Таким образом, по результатам геофизических исследований в изучаемом геологическом разрезе выделяется 7 геоэлектрических горизонтов.

Из таблицы видно, что породы дифференцируются по сопротивлениям в зависимости от их дисперсности. Полученный диапазон изменений УЭС в одновозрастных породах объясняется неоднородностью отложений (прослоями песчаников и мергелей).

Результаты интерпретации геофизических данных позволили дополнить данные инженерногеологических изысканий по изучаемой территории. На глубине 8 м на всех кривых (графиках) кругового ВЭЗ отмечается уменьшение значений УЭС, что соответствует уровню грунтовых вод. На глубине в среднем 11-12 м на кривых ВЭЗ отмечается изменение величин УЭС, соответствующее смене рыхлых оползневых грунтов на более плотные породы. Геоэлектрическая граница в изучаемом массиве отмечается также на глубине 20-22 м. Ниже 40-55 метров наблюдается геоэлектрический горизонт со значениями УЭС 25-50 Ом·м, соответствующий сеноманским пескам.

На основании вышеизложенного можно сделать следующие выводы.

- Проведенные геофизические исследования позволили определить глубину охвата оползня и граничные условия оползневого массива.

- Поверхность смещения современного оползня образована по высокопластичным гли- нам, зеркало оползня имеет циркообразную форму с крутыми стенами срыва, многочисленными глубокими трещинами растяжения.

- В оползневом теле сформировался постоянно действующий уровень грунтовых вод на отметке примерно 178 м с подпиткой дождевыми и талыми водами по зияющим трещинам, а также разгрузкой в оползень подземных вод сызранского и, возможно, локально маастрихтского горизонтов.

- Оползень не достиг еще своего низшего устойчивого положения, энергия, создаваемая весом грунтовых масс с верховой стороны и гидростатическим давлением подземных вод, не израсходована, оползневые массы продолжают утяжеляться, а трещины отрыва и растяжения интенсивно развиваются. Активизация оползня носит циклический характер и интенсифицируется в период затяжных дождей, ливней и активного снеготаяния.

- Для выработки проектных решений в дополнение к пройденным профилям необходимо исследовать оползневой массив дополнительными двумя поперечными и тремя-четырьмя продольными профилями.

- Для определения динамических характеристик оползневого массива необходимо проводить постоянный геолого-геофизический мониторинг на специально выделенных контрольных участках (КУ), используя как контактные, 
так и всепогодные бесконтактные геофизические методы исследований ${ }^{1}$.

- В геологическом строении склонов на территории Саратова отмечается наличие пород песчано-глинистого состава, что обусловливает приуроченность оползней к породам почти всех геологических возрастов, начиная от древних коренных пород юрского и мелового возраста и заканчивая современными отложениями четвертичной системы. Кроме того, для коренных пород в районе Саратова характерна тектоническая нарушенность, что обусловливает наличие зон повышенной трещиноватости и смещения. В таких зонах прочностные параметры пород ослаблены. Способствуют образованию оползней и морфологические условия склонов Соколовогорского и Лысогорского массивов, в первую очередь их высота до 100-120 м и значительная крутизна (до 40-45²). Морфологические условия способствуют развитию эрозии, абразии, суффозии, обвально-осыпных процессов, выветриванию, что негативно сказывается на устойчивости склонов. Важным фактором возникновения оползней являются гидрогеологические условия. Горизонты грунтовых вод приурочены к пескам, трещиноватым глинам, опокам. Водоносные горизонты часто напорны и отрицательно действуют на устойчивость склонов.

В целом можно отметить, что активизация оползневых процессов на территории Саратова - процесс постоянный, он затухает или активизируется в зависимости от климатических условий каждого конкретного года, но структурно-тектонический процесс практически не прекращается. В связи с этим обстоятельством отсутствие или сокращение наблюдений за развитием оползневых процессов на городской территории может привести к бесконтрольности и непредсказуемости вероятных катастрофических явлений с разрушениями и жертвами. Необходимо разработать программу борьбы с оползневой опасностью в Саратове и в ближайшее время начать ее реализацию $[7,8]$.
Работа выполнена при финансовой поддержке Федеральной целевой научно-технической программы «Исследования и разработки по приоритетным направлениям развития науки и техники (проведение молодыми ученьмм научных исследований по приоритетным направлениям науки, высоких технологий и образования)» (Госконтракт 02.442.11.7257).

\section{Библиографический список}

1. Иванов А.В., Первушов Е.М. Губковые горизонты сантона-кампана и «птериевые слои» Саратовского Поволжья // Недра Поволжья и Прикаспия. 1998. Вып. 17. C. 24-30.

2. Смилевец О.Д. Исследование приповерхностной части разреза Прикаспийской впадины электроразведкой постоянного тока для электрохимической защиты газопроводов // Там же. 1996. Вып. 11. С. 56-61.

3. Смилевеи О.Д. Применение электроразведки постоянным током при обследовании газопроводов Нижнего Поволжья // Там же. 1998. Вып. 15. С. 60-65.

4. Смилевеи О.Д., Сулиикий Ф.В., Рейтюхов К.С. Особенности проведения электроразведочных работ методом ВЭЗ при обследовании трасс трубопроводов в осенне-зимний период // Там же. 2000. Вып. 24. С. 52-58.

5. Милованов В.И., Смилевец О.Д. Анализ ошибок при работах методом ВЭЗ при обследовании трасс трубопроводов и строительных площадок // Там же. 1999. Вып. 20. C. $48-53$.

6. Смилевец О.Д., Сулииякий Ф.В., Рейтюхов К.С. Особенности интерпретации данных ВЭЗ при расчленении верхней части разреза песчано-суглинистых толщ // Там же. 2001. Вып. 26. С. 67-71.

7. Кузин А.Г. К вопросу о классификации факторов оползневой опасности на урбанизированных территориях (на примере г. Саратова) // Геологи XXI века: Материалы VII Всерос. науч. конф. студ., асп. и молодых спец. Саратов, 2006. C. 119-120.

8. Артемьев С.А., Еремин В.Н., Иванов А.В. и др. Саратов: комплексный геоэкологический анализ / Под ред. А.В. Иванова. Саратов, 2003. 248 с. 